\title{
Da criação ao fechamento - aspectos históricos sobre o primeiro curso de formação de professores (de Matemática) em Ituiutaba - MG
}

\author{
Ivete Maria Baraldi (In memorian) ${ }^{1}$ \\ Douglas Marin ${ }^{2}$
}

\begin{abstract}
RESUMO
Este artigo é parte de um estudo que teve a intenção de elaborar uma versão histórica sobre o movimento de criação dos primeiros cursos de formação de professores (de Matemática), no Triângulo Mineiro, Minas Gerais. Aqui, discutimos mais especificamente sobre os movimentos que vão desde a criação ao fechamento do primeiro curso de Matemática em Ituiutaba. Mobilizamos como metodologia de pesquisa a História Oral, tal qual a concebemos e praticamos no Grupo de Pesquisa História Oral e Educação Matemática - Ghoem. Além das fontes orais foram mobilizadas outras fontes, acessadas em arquivos públicos e privados, e outros trabalhos que nos ajudaram a elaborar compreensões sobre o tema. Apresentamos uma síntese dos resultados, que abrange um movimento de constituição do ensino superior em Ituiutaba, da formação da Faculdade de Filosofia, Ciências e Letras de Ituiutaba e da criação ao fechamento do primeiro curso de formação de professores (de Matemática) nessa localidade.
\end{abstract}

PALAVRAS-CHAVE: Curso Superior de Matemática. História Oral. História da Educação Matemática.

From creation to closure - historical aspects of the first teacher training course (in Mathematics) in Ituiutaba - MG

\footnotetext{
${ }^{1}$ Doutora em Educação Matemática. Universidade Estadual Paulista "Júlio de Mesquista Filho", Bauru, São Paulo, Brasil. Orcid.: https://orcid.org/0000-0001-9779-510X.

${ }^{2}$ Doutor em Educação Matemática. Universidade Federal de Uberlândia, Uberlândia, Minas Gerais, Brasil. Orcid.: https://orcid.org/0000-0002-5798-5176.E-mail: douglasmarin@ufu.br.
} 


\begin{abstract}
This article is part of a study that had the intention to elaborate a historical version about the movement of creation of the first courses of formation of teachers (of Mathematics), in the Triangulo Mineiro, Minas Gerais. Here, we discuss more specifically about the movements that go from the creation to the closing of the first Mathematics course in Ituiutaba. We used Oral History as a research methodology, as we conceived and practiced it in the Oral History and Mathematical Education Research Group - Ghoem. In addition to the oral sources, other sources were used, accessed in public and private archives, and other works that helped us to elaborate understandings on the theme. We present a synthesis of the results, which includes a movement to establish higher education in Ituiutaba, the formation of the Faculty of Philosophy, Sciences and Letters of Ituiutaba and the creation of the first teacher training course (in Mathematics) at that location.
\end{abstract}

KEYWORDS: Higher Mathematics Course. Oral History. History of Mathematical Education.

\title{
Desde la creación hasta el cierre: aspectos históricos del primer curso de formación docente (en Matemáticas) en Ituiutaba - MG
}

\section{RESUMEN}

Este artículo es parte de un estudio que tenía la intención de elaborar una versión histórica sobre el movimiento de creación de los primeros cursos de formación de docentes (de Matemáticas), en el Triangulo Mineiro, Minas Gerais. Aquí, discutimos más específicamente sobre los movimientos que van desde la creación hasta el cierre del primer curso de Matemáticas en Ituiutaba. Utilizamos la Historia Oral como metodología de investigación, tal como la concebimos y practicamos en el Grupo de Investigación de Historia Oral y Educación Matemática Ghoem. Además de las fuentes orales, se utilizaron otras fuentes, a las que se accedió en archivos públicos y privados, y otros trabajos que nos ayudaron a elaborar entendimientos sobre el tema. Presentamos una síntesis de los resultados, que incluye un movimiento para establecer la educación superior en Ituiutaba, la formación de la Facultad de Filosofía, Ciencias y Letras de Ituiutaba y la creación del primer curso de formación docente (en Matemáticas) en ese lugar. 
PALABRAS CLAVE: Curso Superior de Matemáticas. Historia oral.

Historia de la educación matemática.

\section{Introdução}

A história da formação de professores (de Matemática) tem sido foco de diferentes estudos realizados no Brasil, e ganha abrangência nas pesquisas desenvolvidas pelo Grupo de Pesquisa em História Oral e Educação Matemática - Ghoem ${ }^{3}$. Um dos principais projetos desse grupo é elaborar um mapeamento (histórico) sobre a formação e atuação de professores que ensinam/ensinaram de Matemática no Brasil.

Entendemos que esse projeto se propõe a compreender, analisar, elaborar, discutir, estudar depoimentos de professores e outras fontes disponíveis com vistas à constituição de histórias dentro da própria História, abordando a diversidade geográfica, institucional e temporal (GARNICA, 2013; 2018).

Para se desenvolver um trabalho nesta perspectiva, se faz necessário assumir uma determinada postura historiográfica, segundo a qual o estudo do passado, do processo educativo, deve ser disparado pelo presente visando colaborar com o presente - trazendo à tona pressupostos, práticas, atitudes e preconceitos. Nesse sentido, os acontecimentos do passado podem ter diferentes significados, dependendo da forma em que são registrados, interpretados e transmitidos, constituídos em diferentes versões e invenções (ALBUQUERQUE JR, 2007).

Grande parte dos trabalhos desenvolvidos no âmbito do projeto de mapamento, inscreve-se na História da Educação Matemática. Nesse campo de pesquisa, visa-se compreender as alterações e permanências nas práticas relativas ao ensino e à aprendizagem de Matemática; estudar como as comunidades se organizavam no que diz respeito à necessidade de produzir, usar e compartilhar conhecimentos matemáticos e como, afinal de contas, as

\footnotetext{
${ }^{3}$ Para ter mais informações visite http://ghoem.org. Acessado em abr. de 2020. Recomendamos, também, a leitura de Baraldi (2018), Garnica (2018), Martins-Salandim (2018) e Silva (2018).
} 
práticas do passado podem - se é que podem - nos ajudar a compreender, projetar, propor e avaliar as práticas do presente (GARNICA; SOUZA, 2012).

Em sintonia com essas ideias, realizamos uma pesquisa onde estudamos os seis primeiros cursos de formação de professores (de Matemática) no Triângulo Mineiro - Uberaba, Uberlância, Araguari e Ituiutaba. Para esse artigo discutiremos os movimentos que ocorreram na cidade de Ituiutaba, principalmente, por existir aspectos diferentes em relação aos demais cursos.

Podemos adiantar que um deles foi a constituição de todo ensino superior da localidade por meio de cursos isolados ${ }^{4}$. Para entender como isso se deu, além de discutir outros aspectos, elaboramos uma versão histórica, a partir de narrativas mobilizadas por meio de entrevistas de nossos colaboradores, além de outros documentos (MARIN, 2019).

Para tanto, utilizamo-nos da metodologia denominada História Oral, da qual falaremos brevemente a seguir.

\section{História oral: caminho metodológico}

Mobilizamos a História Oral como a metodologia da pesquisa descrita acima, porque entendemos que ela nos auxilia a construir uma versão histórica e também nos credencia a compreender os objetos que pretendíamos focar. Neste caso, em particular, nos permitiu, dentre outras coisas, elaborar uma compreensão acerca da criação do ensino superior e do primeiro curso de formação de professores (de Matemática) em Ituiutaba, Minas Gerais.

Optar pela História oral

[...] não se trata simplesmente de optar pela coleta de depoimentos e, muito menos, de colocar como rivais a escrita e a oralidade. Trata-se de entender a História Oral na perspectiva de, face à impossibilidade de constituir "A" história, (re) construir algumas de suas várias versões, aos olhos dos atores sociais que vivenciaram certos contextos e

\footnotetext{
${ }^{4}$ Discutiremos mais sobre isso, posteriormente. Por enquanto, recomendamos a leitura de Cunha (2007).
} 
situações, considerando como elementos essenciais, nesse processo, as memórias desses atores - via de regra negligenciados -, sem desprestigiar, no entanto, os dados "oficiais", sem negar a importância de fontes primárias, de arquivos, de monumentos, dos tantos registros possíveis (GARNICA, 2007, p.89).

As narrativas resultantes dos depoimentos orais disparam a operação historigráfica, sobre histórias de professores e as histórias contadas por eles, suas vivências e experiências, seus discursos sobre o modo como tais vivências e experiências se deram. As narrativas são as inventoras de práticas. Com elas, criamos realidades, interpretamos vidas e formação de seres humanos ${ }^{5}$. Desse modo, nos estruturamos por meio delas, seja enquanto autores ou quando narradas por outras pessoas, que direta ou indiretamente nos envolvam. Além disso, em Garnica (2010, p. 34-35) temos que nas

narrativas, então, reside a própria possibilidade e potencialidade do que temos chamado História Oral, e tratamos de pensá-las não mais como constituindo "a" história, mas como constituidoras de histórias possíveis, versões legitimadas como verdades dos sujeitos que vivenciaram e relatam determinados tempos e situações. Tanto quanto o é a descrição para a pesquisa qualitativa, as narrativas orais fixadas pela escrita são tomadas como fontes históricas, intencionalmente constituídas, que não estão subjugadas a um critério de valor definido por meio da "realidade" e da "concretude" do mundo.

Embora compreendamos que metodologia não se trate apenas de procedimentos, adotamos uma série de encaminhamentos os quais nos ajudaram na pesquisa. Inicialmente, fizemos contato com alguns depoentes e os demais foram localizados por meio do critério de rede (GARNICA; FERNANDES; SILVA, 2011). Tomamos o cuidado de registrar todas as entrevistas e, por meio do cotejamento com outras fontes, buscamos responder "Como se deu o movimento de criação dos primeiros cursos de

\footnotetext{
${ }^{5}$ Para um maior aprofundamento, recomendamos Garnica (2014; 2015; 2018), Morais (2017) e (Garnica; Gomes, 2020).
} 
formação de professores (de Matemática) no Triângulo Mineiro, Minas Gerais?", nossa questão de pesquisa.

Para compor essa história, tomamos os primeiros cursos de formação de professores (de Matemática) como os balizadores temporais do estudo, assim, essa pesquisa está compreendida entre 1960 a 1980. Tivemos como colaboradores professores e alunos que, de algum modo, vivenciaram os ambientes dos primeiros cursos de formação de professores (de Matemática) no Triângulo Mineiro, dessa forma, foi possível entrevistar quinze pessoas nas cidades de Uberlândia, Uberaba, Ituiutaba e Araguari.

Nesse artigo, focamos na cidade de Ituiutaba, tivemos um curso de licenciatura em Matemática, instalado em 1970, na Faculdade de Filosofia, Ciências e Letras de Ituiutaba. Concederam entrevista os professores Vanderli Anacleto de Campos, Julmar de Oliveira Diniz e a professora Maria Mirza Cury Diniz que, de algum modo, vivenciaram o movimento de criação do ensino superior e do curso de Matemática, nessa localidade.

Após as entrevistas, os depoimentos gravados passaram por um processo chamado transcrição, constituindo um primeiro registro escrito dos diálogos ocorridos entre pesquisadores e colaboradores. Os depoimentos transcritos passaram, posteriormente, pelo momento de textualização, gerando um texto conjunto de autoria dos pesquisadores com os entrevistados ${ }^{6}$ Entendemos que o resultado é uma construção coletiva, para a qual contribuíram as análises, troca de ideias, supressões e acréscimos de entrevistado e pesquisadores (BARALDI, 2003).

No conjunto das fontes disponíveis e criadas com as entrevistas, foi possível traçar algumas compreensões sobre os aspectos da criação do primeiro curso de formação de professores (de Matemática) em Ituiutaba, aos quais narramos no que segue.

\footnotetext{
${ }^{6}$ Cumpre esclarecer que todos os nossos colaboradores assinaram documentos nos quais autorizam a divulgação de seus nomes e cederam a nós os direitos quanto às gravações, transcrições e textualizações de suas entrevistas.
} 


\section{Sobre o primeiro curso de formação de professores (de Matemática) em Ituiutaba}

A criação do primeiro curso de formação em nível superior para lecionar Matemática em Ituitaba, se confunde com o movimento de criação do ensino superior nessa localidade. De acordo com a professora Maria Mirza, "houve em Ituiutaba, uma tentativa de abertura de uma Universidade, na década de 1960" (Narrativa de Maria Mirza Cury Diniz in Marin, 2019, p. 173).

Segundo Silva e Quillici Neto (2011), a autorização de funcionamento de uma fundação denominada Fundação Universidade do Triângulo Mineiro foi autorizada a partir da Lei estadual $\mathrm{n}^{0} 2.914$, de 30 de outubro de 1963, com o objetivo de manter e criar uma universidade em Ituiutaba, que teria o nome de Universidade do Triângulo Mineiro.

À época, esta Instituição não saiu do papel, pois não cumpria os critérios apontados na Lei $\mathrm{n}^{0} 4.024$, de 1961, na qual se previa que as universidades só se constituiriam pela unificação de cinco ou mais instituições de ensino superior.

Ainda, Silva e Quillici Neto (2011) apontam que apenas em 1968, com a nomeação do Conselho Curador da Fundação, a primeira instituição de ensino superior de Ituiutaba começou a ser desenhada e esse Conselho optou pela criação de uma Faculdade de Filosofia, Ciências e Letras. Também temos que levar em consideração que em 1968 foi aprovada a Lei $\mathrm{n}^{0} 5.540$ (BRASIL, 1968), que tratava de reorganizar o ensino superior e isso pode ter direcionado os encaminhamentos para a abertura de uma faculdade.

Por não ter um lugar específico para funcionar, o ensino superior, em Ituiutaba, começou, em 1968, a partir da criação de cursos isolados, que foram amparados em diferentes colégios da cidade. De acordo com a nossa colaboradora, a professora Maria Mirza: 
[...] no começo, os cursos que existiam eram espalhados por alguns colégios da cidade. Era no Colégio São José ${ }^{7}$ o Instituto Marden ${ }^{8}$ e o Colégio Santa Teresa ${ }^{9}$. O curso de Matemática também nasceu nesse movimento de cursos espalhados (Narrativa de Maria Mirza Cury Diniz in Marin, 2019, p. 174).

A constituição de instituições de ensino superior, por intermédio de cursos isolados, não é uma característica particular de Ituiutaba. Isso ocorreu desde o início do desenvolvimento do ensino superior no Brasil, quando da chegada da família imperial, em 1808 (VASSELAI, 2001; MASETTO, 2008). Mais recentemente, temos que esse movimento aconteceu em Tocantins (CURY, 2011) e no Mato Grosso do Sul (SILVA, 2015) quando da emancipação dos respectivos estados do Tocantins e de Mato Grosso do Sul.

Corroborando o que foi dito por Maria Mirza, o professor Julmar de Oliveira Diniz afirmou que "no início, os cursos ocupavam as salas de aula de alguns colégios da cidade, o Instituto Marden, o Colégio São José, porque não havia prédio" (Narrativa de Julmar de Oliveira Diniz in Marin, 2019, p. 168). Nossos colaboradores apontaram que os cursos de ensino superior que estavam espalhados pelos colégios da cidade eram o de Pedagogia, História, Ciências Biológicas, Letras e Matemática.

Sobre o curso de formação de professores, Vanderli Anacleto Campos, que lecionou Estatística nesses cursos iniciais, apontou que, à época, "usávamos as instalações do Colégio São José para lecionar para nossos estudantes do curso de Matemática" (Narrativa de Vanderli Anacleto de Campos in Marin, 2019, p. 162).

Os cursos de formação de professores em Ituiutaba sofreram uma alteração quando a Fundação Universidade do Triângulo Mineiro recebeu, pelo Decreto Estadual n 66.602, de maio de 1970, a autorização

\footnotetext{
${ }^{7}$ Criado em 1940, foi a primeira instituição confessional direcionada à formação masculina em Ituiutaba, ligado à Congregação Estigmatina, deixou de funcionar em 1971 (PACHECO, 2012).

${ }^{8}$ Instituto Marden foi criado em 1933, atendia meninos e meninas, era de origem laica e particular. A escola encerrou suas atividades em 1979 (MORAES, 2004).

${ }^{9}$ Criada em 1939, atendia meninos e meninas, após a construção do prédio novo o colégio dedicou-se a educação de meninas, ligado à Congregação das Irmãs Scalabrinianas. Funciona até os dias atuais (OLIVEIRA, 2009).
} 
para funcionar a Faculdade de Filosofia, Ciências e Letras de Ituiutaba, com os cursos que já existiam.

Antes de ser criada a Faculdade de Filosofia, Ciências e Letras de Ituiutaba, Maria Mirza relata que a mantenedora da Fundação Universidade do Triângulo Mineiro cogitava abrir outras Faculdades com cursos de nível superior.

No começo, [a mantenedora] queria implantar uma Faculdade de Ciências Agrárias, por causa da natureza da região, pelo fato da cidade ser agropecuária. Éramos a capital do arroz. Mas depois de alguns estudos sobre a cidade e a região, foi decidido abrir uma Faculdade de Filosofia, Ciências e Letras pela carência muito grande de professores habilitados para atuarem nas escolas (Narrativa de Maria Mirza Cury Diniz in Marin, 2019, p. 174).

Com a intensificação das discussões acerca da criação de instituições para o ensino superior, ou de cursos, à época, Maria Mirza era docente no Colégio São José e diretora do Grupo Escolar Governador Clóvis Salgado10, devido a isso, ela foi convidada a participar dessas discussões na cidade.

[...] Em uma reunião, discutimos a importância de um outro curso superior na cidade, lembro-me que alegavam que isso iria trazer muitos jovens para Ituiutaba e que poderia melhorar até os casamentos. Ficamos muito entusiasmados com tudo isso. (Narrativa de Maria Mirza Cury Diniz in Marin, 2019, p. 174).

Esse novo curso a que a professora se refere era Administração de Empresas e seria instalado na Escola de Administração de Empresas de Ituiutaba (EAEI), aprovada em 1968. Porém, esse curso iniciou as suas atividades apenas em 1970, depois que a Faculdade de Filosofia começou a funcionar nas instalações do Instituto Marden (SILVA; QUILLICI NETO, 2011).

\footnotetext{
${ }^{10}$ Foi criado pelo projeto de Lei apresentado à Assembléia Legislativa do Estado de Minas Gerais através do então Deputado Estadual da região, Dr. Omar de Oliveira Diniz, 1956, que foi aprovado pelo governador interino do Estado, Dr. Clóvis Salgado, iniciando suas atividades em 17 de julho de 1957. O prédio definitivo foi inaugurado em fevereiro de 1960. Em 2020 ainda estava em funcionamento. (MARIN, 2019).
} 
Pacheco e Lopes (2009) apontam que a partir de 1972, a EAEI começou a funcionar em sede própria. Apenas em 1975, essa instituição e o curso oferecido foram reconhecidos. Depois, em 1983, a EAEI passou a chamar-se Escola Superior de Ciências Administrativas de Ituiutaba (Escai), porém, em 1985, em função da instalação do curso de Ciências Contábeis, fez-se necessária outra mudança e a Escai passou a ser denominada Escola Superior de Ciências Contábeis e Administrativas de Ituiutaba (Esccai) (SILVA, 2013). A partir de 2002, com a criação dos cursos de Publicidade e Propaganda e Turismo, recebeu a denominação de Faculdade Triângulo Mineiro (FTM), ainda em funcionamento.

Em relação à Faculdade de Filosofia, a partir do apoio da prefeitura, iniciou-se a construção de um local próprio. Maria Mirza nos narra que "começaram a construir um primeiro prédio no câmpus que existe até hoje. Quando o curso de Matemática foi levado para esse câmpus, ele já estava no terceiro ano de funcionamento da primeira turma" (Narrativa de Maria Mirza Cury Diniz in Marin, 2019, p. 173).

De forma similar ao que a professora Mirza disse, o professor Julmar deu um pouco mais de detalhes:

[...] primeiro foi construído um prédio e depois, bem devagar, foram sendo construídos outros, mas não posso deixar de mencionar que, nessa época, a Faculdade obteve a ajuda do deputado Romel Anísio Jorge ${ }^{11}$ para a construção de outros prédios, inclusive um deles leva o nome do seu pai (Narrativa de Julmar de Oliveira Diniz in Marin, 2019, p. 168).

Um dos primeiros professores a lecionar no curso de Matemática, na sede própria, foi Vanderli Anacleto Campos.

Lembro-me que, em 1972, a Faculdade passou a ter a sede própria e fui o primeiro professor a lecionar no câmpus novo,

\footnotetext{
11 Político da cidade de Ituitaba que, em 1971, filiou-se à Aliança Renovadora Nacional (Arena), elegendo-se vereador por dois mandatos consecutivos. Na Câmara Municipal foi secretário, vice-presidente e presidente, permanecendo na casa até 1977, quando disputou uma vaga na Assembleia Legislativa de seu estado, elegendo-se para o quatriênio 1978-1981. Em 1982 foi prefeito de Ituiutaba. De 1990 até 2002 foi deputado federal. Em 2007, foi nomeado subsecretário de Assuntos Municipais da Secretaria de Governo na gestão de Aécio Neves (MARIN, 2019).
} 
que é no mesmo lugar até hoje. Nesse dia, comecei as aulas às $18 \mathrm{~h} 10$, em um horário extra ${ }^{12}$. A construção era simples. Ela tinha o formato de $\mathrm{H}$, mas não tinha o andar de cima de um dos lados (Narrativa de Vanderli Anacleto de Campos in Marin, 2019, p. 162 e 163).

Essa memória do professor Vanderli nos chamou a atenção, quando localizamos na Revista Documenta (174), de 1975, o parecer de autorização de funcionamento da Faculdade:

[...] o prédio em que funciona a Faculdade de Filosofia, Ciências e Letras de Ituiutaba é uma construção recente, em estilo moderno, no formato de um $\mathrm{H}$, com um saguão central para a recreação, todos eles em dois pavimentos. Dos quatro blocos previstos e interligados, três estão completamente construídos (Documenta (174), 1975, p. 317 - 318).

No ano de 1973, houve uma mudança na denominação da Fundação Universidade do Triângulo Mineiro, que passou a ser chamada de Fundação Educacional de Ituiutaba (Feit). Essa mudança na nominação da mantenedora coincide com a instalação da Faculdade de Filosofia, Ciências e Letras em um local próprio. Segundo a professora Mirza, isso foi tão significativo entre professores, funcionários, estudantes e população da cidade, que passaram a chamar o local de Feit, mesmo depois que foram abertas outras faculdades.

No mesmo ano de criação da Feit, a mantenedora obteve autorização para a criação da Faculdade de Engenharia de Ituiutaba, com a instalação do curso de Engenharia Elétrica. Depois, em 1984, foi autorizado o funcionamento da Faculdade de Ciências Agrárias, com o curso de Agronomia (SILVA; QUILLICI NETO, 2011).

Em fevereiro de 1986, houve uma mudança na estrutura organizacional da instituição, com a criação do Instituto Superior de Ensino e Pesquisa de Ituiutaba (Isepi). Segundo o professor Julmar, com a criação

\footnotetext{
12 Era comum a direção da Faculdade colocar aulas às $18 \mathrm{~h} 10$ para conciliar horários de professores que lecionavam em outros locais (MARIN, 2019).
} 
desse Instituto houve uma fusão das faculdades de Filosofia, Agronomia e Engenharia pela Feit.

Em 1989, houve um outro acontecimento para o ensino superior de Ituiutaba. O professor Vanderli aponta que, com a promulgação da Constituição Mineira ${ }^{13}$, neste ano, criou-se a possibilidade da estadualização dos cursos mantidos pela Feit, ao integrarem-se à Universidade do Estado de Minas Gerais (UEMG). Esse acontecimento seria importante para a cidade e região, pois passaria a existir nessa localidade uma instituição pública, uma vez que os cursos mantidos na Feit eram todos pagos. No entanto, esse processo não se concretizou. A partir da narrativa do professor Vanderli, entendemos que a Feit tornou-se a primeira unidade agregada à UEMG, sendo reconhecida como um campus fundacional. Silva e Quillici Neto (2011) fazem a mesma ressalva e acrescentam que os cursos oferecidos continuavam a ser pagos.

Quando realizamos a primeira visita ao câmpus da Feit em 2016, soubemos que a Instituição havia passado pela estadualização. Isso ocorreu em abril de 2014, pelo Decreto Estadual no 46.478. Desse modo, a Feit deixou de existir, tornando-se a partir daquela data mais um câmpus da UEMG14.

Neste período de transição e de mudanças na gestão da instituição, o curso de Matemática sofreu uma adequação, que não foi a única durante sua existência. Anterior a isso, identificamos na Documenta (229), de 1979, a conversão do curso de Matemática em um curso de Licenciatura em Ciências, com habilitação em Biologia e em Matemática.

A partir de outros documentos cedidos pela direção da instituição, identificamos que, em 2002, o curso onde o professor se formava para lecionar Matemática foi convertido para uma Licenciatura em Matemática. Nesse mesmo ano, entendemos pela narrativa da professora Maria Mirza, que houve na Feit uma mudança que afetou todos os cursos de licenciatura.

\footnotetext{
${ }^{13}$ Constituição do Estado de Minas Gerais, em 21/09/1989.

${ }^{14}$ Para mais informações sobre a UEMG, ver em 〈http://www.uemg.br/>. Acesso em 19 set.2018.
} 
Isso se deu a partir da criação do Instituto Superior de Educação de Ituiutaba (Isedi). Maria Mirza foi a primeira coordenadora do Isedi.

Esse Instituto continuou ligado à mantenedora e era o responsável por administrar todos os "cursos de formadores de profissionais para a Educação Básica, isto é, para a Educação Infantil, Ensino Fundamental e Ensino Médio” (Narrativa de Maria Mirza Cury Diniz in Marin, 2019, p. 174).

Segundo a mesma professora, a partir da criação do Isedi "houve uma melhora na assessoria administrativa, financeira e pedagógica através de palestras e cursos para os professores e alunos da instituição" (Narrativa de Maria Mirza Cury Diniz in Marin, 2019, p. 174).

Apesar dessa nova possibilidade para os cursos de licenciatura da Feit, por meio do amparo que se estabeleceu pelo Isedi, isso não foi suficiente para evitar que fosse extinto o curso de Matemática, em 2008. Segundo o professor Vanderli Anacleto Campos, "a principal razão para o seu fechamento foi a falta de alunos" (Narrativa de Vanderli Anacleto de Campos in Marin, 2019, p. 164).

Baseados na narrativa do professor Vanderli, que afirmou que uma das razões desse fechamento se deveu à falta de alunos, aventamos a possibilidade que isso tenha ocorrido devido ao oferecimento de um novo curso de formação de professores (de Matemática) em Ituiutaba, ligado à Universidade Federal de Uberlândia - UFU.

Quando foi aberto em Ituiutaba um novo câmpus da UFU, a Instituição ainda não tinha um local próprio para funcionar. Isso fez com que os cursos de ensino superior, que estavam sob a sua administração, ficassem espalhados pela cidade, muitos deles ficaram instalados no câmpus da Feit.

No ano de 2006, foi iniciado um curso de Licenciatura em Matemática mantido pela UFU. Esse curso funcionava na Feit inicialmente e concorria com o seu próprio curso de Matemática e que era pago pelos alunos. A criação desse novo curso em uma instituição pública contribuiu para que o curso de formação de professores (de Matemática) da Feit ficasse sem alunos e, consequentemente, deixasse de ser oferecido. 
Todos esses aspectos levantados por nós, disparados a partir das entrevistas de nossos colaboradores, formaram um conjunto de indícios que nos direcionam a perceber esses movimentos que vão da criação ao fechamento do curso de formação de professores (de Matematica) na Faculdade de Filosofia, Ciências e Letras de Ituiutaba.

\section{Considerações finais}

Percebemos a necessidade de apresentar algumas considerações que podem nos ajudar em outros entendimentos que margeiam o primeiro curso de formação de professores (de Matemática) em Ituiutaba, que iniciou no final da década de 1960.

Um primeiro aspecto, que entendemos ser importante abordar, refere-se à estruturação do ensino superior em Ituiutaba. Esse movimento começou em 1968, a partir da criação de cursos isolados que funcionavam em diferentes colégios da cidade, o que não foi uma característica particular de Ituiutaba.

Cunha (2007) aponta que a estruturação do ensino superior no país deuse inicialmente sob a forma de cadeiras, que foram sucedidas por cursos isolados, posteriormente, por escolas isoladas, passando para faculdades isoladas, sendo a iniciativa privada responsável pela instalação da maioria delas.

Por meio do cotejamento das narrativas com outras fontes, entendemos que o movimento de constituição do ensino superior em Ituiutaba passou por esse processo descrito em Cunha (2007) e, ainda que a Faculdade de Filosofia, Ciências e Letras de Ituiutaba era mantida pela iniciativa privada constituída por empresários da cidade.

Outro aspecto, trata-se da Instituição que abrigava o primeiro curso de formação de professores (de Matemática) ser uma faculdade de filosofia. Sobre isso, em seu estudo, Martins-Salandim (2012) discute que a partir da década de 1960, as Faculdades de Filosofia, Ciências e Letras, acabaram por se multiplicar, isoladamente, acompanhando a tradição do ensino superior brasileiro, isso também percebemos que ocorreu em Ituiutaba. 
Essa mesma autora, ainda aponta que esse movimento de crescimento das faculdades de filosofia tinha como objetivo responder à pressão por ensino superior de uma sociedade em processo de mudança, com crescente aspiração a esse nível de ensino, com o objetivo de formar o professor para atuar no ensino secundário.

Pelas entrevistas dos professores, ficou evidente que a intenção do curso de Matemática que existiu em Ituiutaba era a de formar o professor para lecionar no ensino secundário e, segundo essa determinação, o curso era conduzido.

Vale lembrar que apresentamos um recorte de uma pesquisa maior, e que nosso trabalho, materializado nesse artigo, representa uma contribuição para a compreensão dos movimentos em torno da criação do primeiro curso de formação de professores (de Matemática) em Ituiutaba.

\section{Referências}

ALBUQUERQUE JR, D. M. História: a arte de inventar o passado. Bauru, SP: Edusc, 2007.

BARALDI, I. M. Retraços da Educação Matemática na região de Bauru (SP): uma história em construção. 2003. Tese (Doutorado em Educação Matemática) - Instituto de Geociências e Ciências Exatas, Universidade Estadual Paulista "Júlio de Mesquita Filho", Rio Claro/SP, 2003.

BARALDI, I. M. Grupo de Pesquisa História Oral e Educação Matemática: dos estudos sobre História da Educação Matemática (Inclusiva). Revista de História da Educação Matemática - Histemat, ano 4, n.3, p.93-103, 2018.

BRASIL. Lei n. 5.540, de 28 de Novembro de 1968. Fixa normas de organização e funcionamento do ensino superior e sua articulação com a escola média, e dá outras providências. (1968). Disponível em: <https://www2.camara.leg.br/legin/fed/lei/1960-1969/lei-5540-28-novembro1968-359201-publicacaooriginal-1-pl.html > Acesso em: 10 nov. 2020.

CUNHA, L. A. A Universidade Reformanda: o golpe de 1964 e a modernização do ensino superior. São Paulo: Editora UNESP, 2007. DOI: https://doi.org/10.7476/9788539304561. 
CURY, F. G. Uma história da formação de professores de Matemática e das Instituições formadoras do estado do Tocantins. 2011. Tese (Doutorado em Educação Matemática) - Instituto de Geociências e Ciências Exatas, Universidade Estadual Paulista "Júlio de Mesquita Filho", Rio Claro/SP, 2011.

DECRETO $n^{\circ} 46.478$, de 03 de abril de 2014. Regulamenta a absorção, pela Universidade do Estado de Minas Gerais, das atividades de ensino, pesquisa e extensão mantidas pela Fundação Educacional de Ituiutaba, 2014. Disponivel em: <http://www.2018.uemg.br/downloads/DECRETO46478.pdf>. Acesso em: 30 mar. 2020.

DECRETO $n^{\circ}$ 66.602, de 20 de Maio de 1970 . Autoriza o funcionamento da Faculdade de Filosofia, Ciências e Letras de Ituiutaba, no Estado de Minas Gerais, 1970. Disponivel em: $<$ https://www2.camara.leg.br/legin/fed/decret/1970-1979/decreto-66602-20maio-1970-408048-publicacaooriginal-1-pe.html>. Acesso em: 30 mar. 2020.

DOCUMENTA. Rio de Janeiro: Conselho Federal de Educação. v. 229, dez. $/ 1979$.

DOCUMENTA. Rio de Janeiro: Conselho Federal de Educação. v. 174, jul. /1975.

GARNICA, A. V. M., FERNANDES, D. N.; SILVA, H. Entre a Amnésia e a Vontade de nada Esquecer: notas sobre regimes de historicidade e história oral. Bolema, 25(41), 213-250, 2011.

GARNICA, A. V. M; SOUZA, L. A.. Elementos de História e de Educação Matemática. São Paulo: Cultura Acadêmica, Unesp, 2012.

GARNICA, A. V. M. História Oral e Educação Matemática. In: M. C. Borba \& J. L. Araújo (org.). Pesquisa Qualitativa em Educação Matemática (p. 77 98). Belo Horizonte: Autêntica, 2007.

GARNICA, A. V. M. Presentificando Ausências: A Formação e a Atuação dos Professores De Matemática. In: CUNHA, A.M. de O. (org.). Convergências e tensões no campo da formação e do trabalho docente. Belo Horizonte: Autêntica, 2010.

GARNICA, A. V. M. Cartografias contemporâneas: mapa e mapeamento como metáforas para a pesquisa sobre formação de professores de Matemática. ALEXANDRIA Revista de Educação em ciências e Tecnologia, v.6, n.1, p. 35- 60, 2013. 
GARNICA, A. V. M. (Org.). Cartografias Contemporâneas: Mapeando a Formação de Professores de Matemática no Brasil. Curitiba: Appris, 2014.

GARNICA, A. V. M. História oral em educação matemática: um panorama sobre pressupostos. História Oral, v. 18, n. 2, p. 35-53, jul./dez. 2015

GARNICA, A. V. M. Grupo de Pesquisa História Oral e Educação Matemática: mapeamento da formação e atuação de professores que ensinam/ensinaram matemática no Brasil. Revista de História da Educação Matemática - Histemat, ano 4, n.3, p.68-92, 2018.

GARNICA, A. V. M.; GOMES, M. L. M. História oral: diversidade, pluralidade e narratividade em educação matemática. In: GONÇALVES, H. L. J. (Org.). Educação Matemática \& Diversidade(s). Porto Alegre, RS: Editora Fi, 2020. Disponível em: <https://www.editorafi.org/30matematica>. Acesso em: 10 nov. 2020.

MARIN, D. Uma história da criação dos primeiros cursos de formação de professores (de Matemática) no Triângulo Mineiro - Minas Gerais. 2019. Tese (Doutorado em Educação para Ciência) - Universidade Estadual Paulista "Júlio de Mesquita Filho", Rio Claro, SP, 2019.

MARTINS-SALANDIM, M. E. Grupo de Pesquisa História Oral e Educação Matemática: dos estudos sobre Hermenêutica de Profundidade. Revista de História da Educação Matemática -Histemat, ano 4, n.3, p.133-146, 2018.

MARTINS-SALANDIM, M. E. A interiorização dos cursos de Matemática no estado de São Paulo: um exame da década de 1960. 2012. Tese (Doutorado em Educação Matemática) - Instituto de Geociências e Ciências Exatas, Universidade Estadual Paulista "Júlio de Mesquita Filho", Rio Claro/SP, 2012.

MASETTO, M.T. Formação continuada de docentes no ensino superior numa sociedade do conhecimento. Mesa redonda. In: I Colóquio Internacional sobre ensino superior. Feira de Santana: UEFS, 2008. Anais ... Feira de Santana: UEFS, 2008.

MORAES, V. C. O. Tudo pela pátria: a história do Instituto Marden (193345). 2004. Dissertação (Mestrado em Educação)-Faculdade de Educação da Universidade Federal de Uberlândia, Uberlândia.

MORAIS, M.B. Se um viajante... percursos e histórias sobre a formação de professores de Matemática no Rio Grande do Norte. 2017. Tese (Doutorado em Educação Matemática) - Instituto de Geociências e Ciências Exatas, Universidade Estadual Paulista "Júlio de Mesquita Filho", Rio Claro/SP, 2017. 
OLIVEIRA, L. H. M.M. Entre a Memória e o arquivo: o Colégio Santa Teresa em Ituiutaba. In SOUZA, S. T.; RIBEIRO, B. O. L. (Orgs). Do público ao privado, do confessional ao laico: a história das instituições escolares na Ituiutaba do século XX. Uberlândia: Edufu, 2009.

PACHECO, S.B.N.; LOPES, L. H. F... Escola de Administração de Empresas de Ituiutaba: um estudo preliminar sobre a criação e a implantação da primeira instituição de ensino superior do Pontal do Triângulo Mineiro (1968-1970). In: Seminário Internacional de Educação do Pontal do Triângulo Mineiro, Ituiutaba, 2009. Anais... Ituiutaba: FACIP/UFU, 2009.

PACHECO, S. B. N. Colégio São José: gênese e funcionamento da escola dos estigmatinos em Ituiutaba-MG (1940-1971). 2012. Dissertação (Mestrado em Educação) - Faculdade de Educação, Universidade Federal de Uberlândia, Uberlândia/MG, 2012.

SILVA, M. A.; QUILLICI NETO, A. A expansão do ensino superior no Pontal do Triângulo Mineiro: uma análise da influência da Lei 5.540/68. In: VI Congresso de Pesquisa e Ensino de História da Educação em Minas Gerais, 2011, Viçosa/MG. Anais... Viçosa: UFV, 2011.

SILVA, M. A.. Análise histórica da influência da Faculdade Triângulo Mineiro (FTM) na formação de bacharéis em Administração e Contabilidade: décadas de 1970 a 2000. In: VII Congresso Brasileiro de História da Educação, 2013, Cuiabá. Anais... Cuiaba: UFMT, 2013.

SILVA, C.R.M. Uma, nove ou dez narrativas sobre as licenciaturas em Ciências e Matemática em Mato Grosso do Sul. 2015. Tese (Doutorado em Educação Matemática) - Instituto de Geociências e Ciências Exatas, Universidade Estadual Paulista “Júlio de Mesquita Filho", Rio Claro/SP, 2015.

SILVA, H. Grupo de Pesquisa História Oral e Educação Matemática: dos estudos sobre intervenções na formação de professores. Revista de História da Educação Matemática -Histemat, ano 4, n.3, p.103-119, 2018.

VASSELAI, C. As Universidades Confessionais no Ensino Superior Brasileiro: identidades, contradições e desafios. 2001. Dissertação (Mestrado) - Faculdade de Educação, Universidade Estadual de Campinas, Campinas/SP, 2001. 